\title{
Hemoconcentration in hemolytic uremic syndrome: time to review the standard case definition?
}

\author{
Alejandro Balestracci • Sandra Mariel Martin • \\ Ismael Toledo
}

Received: 26 September 2014 / Revised: 29 September 2014 / Accepted: 30 September 2014 / Published online: 26 October 2014

(C) IPNA 2014

Sirs,

Hemoconcentration at disease onset has been postulated as a factor of worse prognosis in children with postdiarrheal hemolytic uremic syndrome (D + HUS). Previous studies have demonstrated a significant association between hemoconcentration and severe bowel injury, the need for and longer duration of dialysis, and acute phase death $[1,2]$. In their recent paper published in Pediatric Nephrology, Ardissino and colleagues found in a cohort of 61 patients that hemoconcentration at admission also correlated with major neurological involvement [3].

Of particular importance, given that anemia is a hallmark of the disease but that the more severe cases in their study were associated with little or no anemia, the authors postulate that anemia, based on hematocrit or hemoglobin level, should no longer be considered an absolute diagnostic criterion of D + HUS. Rather, they propose that signs of hemolysis (high lactate dehydrogenase levels, schistocytes, and haptoglobin consumption) should be considered to be equally important indicators for diagnosis, even if anemia is not present at disease onset [3].

In line with their statement, our data provides further support to this notion. Analysis of 154 patients with D + HUS

A. Balestracci · S. M. Martin - I. Toledo

Nephrology Unit, Hospital General de Niños Pedro de Elizalde,

Montes de Oca 40, 1270 Ciudad Autónoma de Buenos Aires,

Argentina

\section{A. Balestracci $(\square)$}

Unidad de Nefrología, Hospital General de Niños Pedro de

Elizalde, 1417 Ciudad Autónoma de Buenos Aires,

Argentina

e-mail: abalestracci@yahoo.com.ar treated in our institution revealed that, regardless of the severity of the disease, a considerable proportion of these patients did not have marked anemia at presentation. Thirty-five patients presented with an initial hematocrit level of $\geq 30 \%$ ( $23 \%)$, of whom $24(16 \%)$ had hematocrit values ranging from 30 to $35 \%$ and the remaining $11(7 \%)$ presented with initial hematocrit levels of $>35 \%$. Remarkably, three patients presented hematocrit levels as high as 44,45 and $49 \%$, respectively.

Because patients with hemoconcentration at admission are at increased risk of severe forms of the disease, early diagnosis is mandatory to provide them with the best therapeutic treatment and to promptly determine whether the child should be transferred to a tertiary care center. However, given that anemia is an absolute diagnosis criterion, diagnosis of D + HUS may be delayed when there is little or no apparent anemia. Consequently, we believe that the revision of the standard case definition of D + HUS proposed by Ardissino et al. [3] should be carefully considered.

\section{References}

1. Balestracci A, Martin SM, Toledo I, Alvarado C, Wainsztein RE (2012) Dehydration at admission increased the need for dialysis in hemolytic uremic syndrome children. Pediatr Nephrol 27(8):14071410

2. Oakes R, Siegler R, McReynolds M, Pysher T, Pavia A (2006) Predictors of fatality in postdiarrheal hemolytic uremic syndrome. Pediatrics 117:1656-1662

3. Ardissino G, Daccò V, Testa S, Civitillo CF, Tel F, Possenti I, Belingheri M, Castorina P, Bolsa-Ghiringhelli N, Tedeschi S, Paglialonga F, Salardi S, Consonni D, Zoia E, Salice P, Chidini G (2014) Hemoconcentration: a major risk factor for neurological involvement in hemolytic uremic syndrome. Pediatr Nephrol. doi:10. 1007/s00467-014-2918-0 